\title{
Seven year overview (2007-2013) of ethical transgressions by registered healthcare professionals in South Africa
}

\author{
Nico Nortjé ${ }^{a, *}$, Willem Hoffmann ${ }^{b}$ \\ ${ }^{\text {a }}$ University of the Western Cape, South Africa \\ ${ }^{\mathrm{b}}$ Tshwane University of Technology, South Africa
}

\section{A R T I C L E I N F O}

Article history:

Received 31 March 2015

Accepted 16 November 2015

Available online 23 February 2016

Keywords:

Ethical transgression

HPCSA

Complaints

\section{A B S T R A C T}

A move has taken place internationally in the delivery and "consumption" of health care where if clients and patients (health care consumers) hold the opinion that the health care professionals/providers' behaviour has had a negative effect, impact or outcome on them, they may lodge a complaint with the relevant health professional regulatory body. Ethical transgressions of health care providers can generally be clustered into the following three categories: a) Competence and conduct with clients (e.g. abandonment, sexual intimacies, dishonesty, disclosure of information); b) Business practices (e.g. billing, reports, documentation); and c) Professional practice (e.g. referral upon termination, obtaining appropriate potential employment opportunities, nonprofessional relationships).

The primary objective of this study was to analyse the ethical transgressions of registered members of the twelve professional boards in the Health Professions Council of South Africa (HPCSA) in the period 2007 to 2013. A mixed methods approach was followed in this study which specifically focused on a historical research approach.

The results indicate that the boards with the highest number of transgressions per the registered practitioners were firstly the Medical and Dental practitioners, closely followed by the Optometry and Dispensing Opticians Board. The predominantly complaint made against members of both these boards was for fraudulent conduct (collectively totalling to $85 \%$ of all fraudulent cases during the period) and included actions such as charging for non-rendered services, issuing false statements and submitting fraudulent medical aid claims.

Cognisance needs to be taken that the South African public will increasingly demand better services and that since they are being better informed via the media of their rights and have access to a broader database of knowledge (rightly or wrongly so the internet) practitioners' opinions will not necessarily be accepted outright and that they (the public) will challenge it accordingly. This raises the concern that practitioners need to take on the responsibility to communicate with their patients/clients in order to educate them and keep them informed.

๑ 2015 The Authors. Publishing services by Elsevier B.V. on behalf of Johannesburg University. This is an open access article under the CC BY-NC-ND license (http:// creativecommons.org/licenses/by-nc-nd/4.0/).

\footnotetext{
* Corresponding author.

E-mail addresses: NNortje@uwc.ac.za (N. Nortjé), HoffmannWA@tut.ac.za (W. Hoffmann).

Peer review under responsibility of Johannesburg University.

http://dx.doi.org/10.1016/j.hsag.2015.11.004

1025-9848/@ 2015 The Authors. Publishing services by Elsevier B.V. on behalf of Johannesburg University. This is an open access article under the CC BY-NC-ND license (http://creativecommons.org/licenses/by-nc-nd/4.0/).
} 


\section{Introduction}

There is an international trend towards consumerism in healthcare settings, especially seen against the rise in private healthcare provision (Fischer, 2015). In many countries this is complemented with advances in human rights principles being imposed around a more patient-centred approach to healthcare (Tritter, 2009). The change from paternalistic healthcare models to a patient-participation model is underpinned by a rights-based approach which focuses on rights and reciprocal duties (also called obligations or prohibitions). Central to this approach is the assumption that patients have rights (e.g. rights to privacy, confidentiality and physical integrity) that can be enforced and that healthcare professionals have a duty to respect and uphold (Tritter, 2009). Thus, it is no surprise that patients who seek medical assistance and/or care have become increasingly well-informed about their rights, as well as the responsibilities and obligations of those providing care. A significant contribution to this awareness is the everexpanding influence of printed and electronic media where information enables patients to pose educated questions, to become more sophisticated consumers, and to appropriately address healthcare professionals' errors and/or misconduct (Thomas, 2005). As such, many patients ("healthcare consumers") are increasingly becoming aware of the structures and processes to lodge a complaint with relevant health professional regulatory bodies when they are of the opinion that healthcare professionals' ("healthcare providers") behaviour have had a negative effect, impact or outcome on them.

In South Africa, the Health Professions Council of South Africa (HPCSA) is a statutory body which was established in terms of the Health Professions Act (No 56 of 1974) to regulate the behaviour of professionals, and which is committed to serving and protecting the public and offering guidance to registered healthcare professionals (Nortjé \& Hoffmann, 2015a). The HPCSA provides a process through which the public can lodge ethical complaints against healthcare professionals they deem to have acted in an unethical way (HPCSA, n.d.).

According to Brüggemann, Wijma, and Swahnberg (2012) an ethical transgression refers to the violation of a specific ethical principle but does not necessarily imply intentional wrongful behaviour. It is important to keep in mind that the obligation to follow one ethical principle can at times be outweighed by the obligation to follow another competing stronger principle in that particular situation. Furthermore, the ethical transgressions of healthcare professionals can generally be clustered into the following three categories: 1) Competence and conduct with clients (e.g. abandonment, sexual intimacies, dishonesty, disclosure of confidential information, providing incompetent patient treatment and/or care); 2) Business practices pertaining to contractual obligations (e.g. fraudulent billing, charging excessive fees, negligent document completion and/or storage, employing non-registered healthcare professionals); and 3) Professional practice (e.g. referral upon termination, nonprofessional relationships) (Saunders, Barros-Bailey, Rudman, Dew, \&
Garcia, 2007; HPCSA, n.d.). It is therefore the duty of the preliminary investigative committee in each HPCSA professional board to consult and liaise with all parties involved, namely the relevant members of the public and/or patient/s, as well as the accused healthcare professional, to ascertain the context and seriousness of the alleged transgression. This will then enable the investigative committee to establish whether the alleged transgression must be dealt with by the HPCSA disciplinary structures or another organ of the state (e.g. a court of law).

The objective of this study was to analyse the ethical transgressions of registered members of all the HPCSA professional boards in the period 2007 to 2013, specifically to ultimately empower healthcare professionals with an understanding of the incidence and qualitative content of ethical transgressions in South Africa. Such a deeper understanding of ethical transgressions can then result in higher levels of professional conduct and patient care.

\section{Methodology}

\subsection{Research design}

A mixed methods approach, specifically an explanatory sequential design (Creswell, 2013), was followed in this study to describe and explain the incidence and qualitative content of ethical transgressions by registered healthcare professionals in South Africa. Initially, quantitative data were collected and analysed to obtain quantitative results, namely the following: the annual number of sanctioned professionals per professional board for the period under review; the incidence of sanctioned professionals and frequency of transgressions per sanctioned professional in each professional board for the total study period; and the frequency of penalties imposed on sanctioned healthcare professionals across the study period. This was followed by qualitative data collection and analysis to identify the main transgression categories and to describe the actual transgression content of each category. Lastly, the qualitative results, specifically the identified transgression categories, were used to analyse quantitative data regarding the frequency of transgressions per transgression categories for each professional board across the total study period.

In order to further strengthen the research design, the study also focused on a historical research approach. The focus of historical research is the interpretation of events that occurred over a specified period of time (Morse \& Field, 1995) with archival material (e.g. documents and records) as the primary data source (Neuman, 1997). In this study the archive refers specifically to the collated information in the annual lists (2007-2013) of professional codes of conduct breaches and ethics misconduct against HPCSAregistered healthcare professionals across all twelve professional boards. These HPCSA annual lists are accessible in the public domain (http://www.hpcsa.co.za/RecentConvitions/ Historical). 


\subsection{Data analysis}

In the quantitative phase of data analysis, annual frequency tables were compiled for the following variable combinations: 1) annual frequency of sanctioned health professionals and guilty verdict cases; 2) annual frequency of penalties imposed on sanctioned health professionals; and 3) frequency of transgression categories linked to sanctioned health professionals. In the qualitative phase of data analysis, the specific case content of each guilty verdict was subjected to a qualitative content analysis (Neuman, 1997). Initially, each of the two researchers independently scrutinised and analysed the content of each case as described in the published annual lists of professional codes of conduct breaches and ethics misconduct against HPCSA-registered healthcare professionals. This was then followed by several discussions between the two researchers until consensus was reached. Note that the individual case descriptions in the publicly available annual lists of ethics transgressions are essentially case summaries that each usually consists of less than two hundred words in length; this should be regarded as a data analysis limitation for the qualitative phase. Furthermore, it should be noted that although the legal framework to guide conduct of a healthcare professional registered with the HPCSA is regulated by the Health Professions Act 56 of 1974, it has been amended a few times over the past 40 years. Until 2010 reference was made to "unprofessional conduct" while the Regulation was changed in 2010 to relate unprofessional conduct to "improper/disgraceful conduct". Since the study data spans over a period of two regulatory periods (i.e. pre2010 and from 2010 onwards), reference to unprofessional conduct will inter alia also mean improper or disgraceful conduct.

\subsection{Ethics approval}

Research projects that exclusively focus on the analysis of publicly available documents are generally exempt from the requirement for ethics clearance from a registered research ethics committee (Department of Health, 2015). As such, no formal ethics clearance was sought for this project. However, In keeping with the ethics principle of anonymity, the sanctioned healthcare professionals' identifying information (i.e. names and HPCSA registration numbers) are not reported in this article even though it is provided in the publicly available archival material.

\section{Results}

This section presents the results from the quantitative and qualitative data analyses respectively in accordance with the explanatory sequential research design. The first set of quantitative results (Table 1 ) focuses on the annual number of sanctioned healthcare professionals per professional board for the period under review (2007-2103).

While the results in Table 1 focuses on the annual frequency of sanctioned healthcare professionals per professional board, it was also important to establish the average number of transgressions per sanctioned professional across the total study period for each of the professional boards (Table 2). As such, this data set provides insight on whether sanctioned healthcare professionals tend to transgress only once or on several occasions.

The next set of quantitative results focuses on the frequency of the various penalties imposed on sanctioned healthcare professionals across the total study period for all professional boards (Table 3). These results provide indications of the frequency, type and extend of penalties imposed by the HPCSA on sanctioned healthcare professionals.

The last set of quantitative results focuses on the frequency of transgressions per transgression category for each professional board across the total study period. This set of results provides valuable indications of the most and least prominent transgression categories for each professional board.

The value of the above quantitative results is enhanced and strengthened by the qualitative data analysis of the respective transgression category content. As such, Table 5 provides descriptions of the salient actual transgression content across the study period. Note that Table 5 also indicates the ten most frequent specific transgressions committed by sanctioned healthcare professionals.

\section{Discussion}

The quantitative results indicate that the HPCSA's professional boards with the highest total number of transgressions in the period 2007 to 2013 were firstly the Medical and Dental healthcare professionals, closely followed by Psychology and then the Optometry and Dispensing Opticians Professional Board (Table 1). In contrast, the Dietetics and Nutrition healthcare professionals and the Speech, Language and Hearing Professions had the highest average number of transgressions per sanctioned healthcare professional (Table 2). The predominant transgression by HPCSA-registered healthcare professionals was fraudulent conduct (Table 4) which included actions such as charging for non-rendered services, issuing false statements and submitting fraudulent medical aid claims (Table 5). On closer inspection, it was found that the general prominent position of fraudulent behaviour amongst healthcare professionals was surpassed by negligence in the treatment of patients amongst the Speech, Language and Hearing Professions and by improper professional role conduct in Board of Psychology and the Dietetics and Nutrition professionals (Table 4). These three transgression categories (fraudulent conduct, negligence/ incompetence in treating and caring for patients, and improper professional role conduct) constituted the largest areas of ethical transgressions amongst the professional boards collectively with fraudulent conduct totalling $51.7 \%$ of all transgressions, negligence/incompetence in treating and caring for patients totalling $24.1 \%$ of all transgressions and improper professional role conduct totalling $13.8 \%$ of all transgressions. These results are similar to international findings as reported by Saunders et al. (2007). The current study's results are also potentially indicative of the changing role of healthcare professionals who are increasingly being 
Table 1 - Annual number of sanctioned healthcare professionals per professional board (2007-2013).

\begin{tabular}{|c|c|c|c|c|c|c|c|c|}
\hline Professional board & 2007 & 2008 & 2009 & 2010 & 2011 & 2012 & 2013 & Total \\
\hline Dental Therapy and Oral Hygiene & 1 & 2 & 4 & 1 & 0 & 1 & 3 & 12 \\
\hline Dietetics and Nutrition & 1 & 0 & 0 & 0 & 0 & 0 & 1 & 2 \\
\hline Emergency Care & 12 & 2 & 2 & 0 & 0 & 2 & 2 & 20 \\
\hline Environmental Health & 1 & 0 & 0 & 0 & 0 & 0 & 0 & 1 \\
\hline Medical and Dental & 84 & 72 & 46 & 59 & 52 & 79 & 107 & 499 \\
\hline Medical Technology & 0 & 1 & 0 & 0 & 0 & 0 & 0 & 1 \\
\hline Occupational Therapy, Medical Orthotics, Prosthetics \& Arts Therapy & 1 & 2 & 0 & 1 & 0 & 1 & 0 & 5 \\
\hline Optometry and Dispensing Opticians & 7 & 1 & 6 & 3 & 1 & 12 & 13 & 43 \\
\hline Physiotherapy, Podiatry and Biokinetics & 8 & 3 & 6 & 3 & 0 & 2 & 10 & 32 \\
\hline Psychology & 9 & 9 & 6 & 8 & 4 & 8 & 5 & 49 \\
\hline Radiography and Clinical Technology & 0 & 1 & 0 & 1 & 0 & 0 & 1 & 3 \\
\hline Speech, Language and Hearing Professions & 5 & 0 & 1 & 3 & 0 & 0 & 2 & 11 \\
\hline TOTAL & 129 & 104 & 71 & 85 & 57 & 109 & 144 & 678 \\
\hline
\end{tabular}

Table 2 - Total number of sanctioned healthcare professionals ( $\%$ of mean annual professionals) and transgressions per sanctioned healthcare professional in each professional board for the total study period (2007-2013).

\begin{tabular}{|c|c|c|c|c|}
\hline Professional board & $\begin{array}{l}\text { Average annual } \\
\text { number of } \\
\text { healthcare } \\
\text { professionals }\end{array}$ & $\begin{array}{l}\text { Total number of sanctioned } \\
\text { healthcare professionals (\% mean } \\
\text { annual professionals) }\end{array}$ & $\begin{array}{l}\text { Total number } \\
\text { of } \\
\text { transgressions }\end{array}$ & $\begin{array}{l}\text { Average number of } \\
\text { transgressions per } \\
\text { sanctioned healthcare } \\
\text { professional }\end{array}$ \\
\hline $\begin{array}{l}\text { Dental Therapy and Oral } \\
\text { Hygiene }\end{array}$ & 3841 & $12(0.31)$ & 31 & 2.58 \\
\hline Dietetics and Nutrition & 2199 & $2(0.09)$ & 7 & 3.50 \\
\hline Emergency Care & 54,666 & $20(0.04)$ & 49 & 2.45 \\
\hline Environmental Health & 2845 & $1(0.04)$ & 2 & 2.00 \\
\hline Medical and Dental & 45,757 & 499 (1.09) & 1121 & 2.25 \\
\hline Medical Technology & 7804 & $1(0.01)$ & 1 & 1.00 \\
\hline $\begin{array}{l}\text { Occupational Therapy, } \\
\text { Medical Orthotics, } \\
\text { Prosthetics \& Arts } \\
\text { Therapy }\end{array}$ & 4685 & $5(0.11)$ & 6 & 1.20 \\
\hline $\begin{array}{l}\text { Optometry and Dispensing } \\
\text { Opticians }\end{array}$ & 3257 & $43(1.32)$ & 84 & 1.95 \\
\hline $\begin{array}{l}\text { Physiotherapy, Podiatry } \\
\text { and Biokinetics }\end{array}$ & 7286 & $32(0.44)$ & 39 & 1.22 \\
\hline Psychology & 10,620 & $49(0.46)$ & 60 & 1.22 \\
\hline $\begin{array}{l}\text { Radiography and Clinical } \\
\text { Technology }\end{array}$ & 7381 & $2(0.03)$ & 2 & 1.00 \\
\hline $\begin{array}{l}\text { Speech, Language and } \\
\text { Hearing Professions }\end{array}$ & 2197 & $11(0.50)$ & 33 & 3.0 \\
\hline TOTAL & 152,541 & $677(0.44)$ & 1437 & 2.12 \\
\hline
\end{tabular}

regarded as healthcare providers/suppliers that focus on profitmaking rather than care as their primary professional goal.

The most common type of penalty imposed (47\%) collectively by all twelve professional boards' ethics committees were financial in nature with fines ranging between R1,000 and R100,000 (Table 3). The highest fines were imposed for offences such as claiming for services not rendered and issuing a fraudulent death certificate. Only 3\% (37 in total) of all the sanctioned healthcare professionals were removed from the register for the following specific transgressions: administering general anaesthetic in an incompetent manner; multiple claims for services not rendered; not adhering to scope of practice; fraudulently issuing sick certificates; having an intimate sexual relationship with a patient; and indecently assaulting a patient. Nortjé and Hoffmann (2015b) argue that it is worrisome that the HPCSA in almost all cases opted to only impose financial and/or suspended suspension period penalties without requiring any form of additional ethical awareness training for the transgressors. The implication is that ethical misconduct may increasingly be regarded by healthcare professionals as merely a business/financial risk but not primarily as an ethics and integrity matter (Nortjé \& Hoffmann, 2015b). As a result, one potential way that healthcare professionals manage this risk could be to merely increase their contributions to a professional liability insurance plan. However, this reaction would not benefit society at large and patients in particular. Rather, the process of changing behaviour inter alia should always include reflection and opportunities to actively challenge healthcare professionals to develop and mature their moral reasoning and ethical conduct skills (Nortjé \& Hoffmann, 2014). 
Table 3 - Frequency of penalties imposed on sanctioned healthcare professionals across the study period (2007-2013).

\begin{tabular}{lcc} 
Penalty & $\begin{array}{c}\text { Total number } \\
\text { of imposed } \\
\text { penalties }\end{array}$ & $\begin{array}{c}\text { \% Of overall } \\
\text { total number of } \\
\text { penalties }\end{array}$ \\
\hline $\begin{array}{l}\text { Caution or Caution-and- } \\
\quad \text { Reprimand }\end{array}$ & 91 & $7 \%$ \\
Fine R1 000 - R8 000 & 251 & $19 \%$ \\
Fine R10 000 - R15 000 & 239 & $18 \%$ \\
Fine R20 000 - R100 000 & 126 & $10 \%$ \\
Suspension 1 month to & 320 & $24 \%$ \\
$\quad$ 1 year & & $18 \%$ \\
Suspension 1.5-4 years & 232 & $1 \%$ \\
Suspension 5-10 years & 19 & $3 \%$ \\
Removal from register & 37 & \\
\hline
\end{tabular}

Fraudulent conduct (51.7\%) and negligence/incompetence in treating/caring for patients (24.1\%) account for threequarters of all the transgressions. The qualitative results regarding these two transgression categories and the specific misconduct committed by sanctioned healthcare professionals provide further insight in the significance of the quantitative results.

\subsection{Fraudulent conduct}

Healthcare fraud is globally and in South Africa a growing problem (Ogubanjo \& Knapp van Bogaert, 2014). Healthcare professionals are generally in a position of trust with clients and/or patients. Any conduct that doesn't honour and respect the trust put in their professional capacity and integrity could negatively impact the healthcare relationship as well as the professional integrity of the profession at large. The current study found that the majority of fraudulent misconduct involved fraudulent medical aid claims where claims are levied for services not rendered or where inappropriate codes were linked to specific procedures with the resultant higher medical aid claim. This type of fraudulent conduct result in indirect harm to the client/patient (i.e. a transgression of the ethical principle of non-maleficence) where the affected persons' medical aid benefits are put at risk of not covering future potential claims when their available funds are depleted (Ogubanjo \& Knapp van Bogaert, 2014). South African legislation takes a firm stance on this issue. According to Section 66 of to the Medical Schemes Act (Act 131 of 1998), fraudulent conduct includes the following:

- To claim for the payment of any benefit allegedly due in terms of the rules of a medical scheme, knowing such claim to be false;

- To make false representation of any material fact to a medical scheme, for use in determining any right to any benefit allegedly due in terms of the rules of the medical scheme;

- To issue a false/inflated statement, account or invoice that may be used to claim from a medical scheme; and

- To charge for psychological services only partially rendered or not rendered at all.

\subsection{Negligence and/or incompetence in evaluating, treating or caring for patients}

Any procedure, intervention or therapy which healthcare professionals might recommend or perform for which they are not duly qualified and for which, when they are compared against the legal rule of a reasonable person/professional and fails, could be regarded as negligent and potentially harmful to the patient/client. In this case, the ethical principle of beneficence (i.e. benefits that should outweigh the risks) is brought into peril; especially so when the healthcare professional's self-deception, which could in some cases be due to professional egoism or arrogance, negatively impacts on the expected restrained conduct. Examples of such incompetent or negligent behaviour in the current study include the following: failure to adequately and/or timeously assess, diagnose and manage or treat a patient's condition; negligent or inappropriate administration, dosage, prescription and/or use of drugs; and failure to refer patients to specialists when indicated by their condition. Such conduct is not only potentially harmful to clients/patients, but can also bring the profession into significant disrepute.

\section{Conclusion and recommendations}

A significant finding of this study is that fraudulent conduct and negligence and/or incompetence in evaluating, treating or caring for patients are the most frequent categories of ethical transgressions amongst HPCSA-registered healthcare professionals for the period 2007 to 2013. As such, one can conclude that there have been important changes in the professional/patient relationship in consumerism-based healthcare settings where business practices might enjoy a significant focus of healthcare and where many ethical transgressions may be motivated by financial gains and/or incentives. This supports the notion that consumerism in healthcare settings is increasingly emerging in South Africa which could ultimately severely compromise the care aspect of healthcare, specifically with regards to negligent and/or incompetent conduct by healthcare professionals.

In conclusion, the following recommendations are offered:

- In the South African consumer-orientated non-socialised healthcare system it should be imperative to be cognisant of and to adhere to international governance models as not to negatively impact on the healthcare provision model. As such, it is vital that the healthcare system in a consumerist society must also adhere to widely-recognised consumerism principles, specifically transparency, integrity, best interest conduct, competence, risk management and compliance with laws, rules, codes and standards (Institute of Directors in Southern Africa, 2009).

- Ethics awareness amongst healthcare professionals should involve more than mere awareness and/or adherence to the HPCSA codes of conduct. The intention of these codes is not to facilitate mere compliance with the "letter of the law" but rather to engage and challenge healthcare 
Table 4 - Total number (percentage) of transgressions per transgression categories for each professional board across the total study period.

Professional board (total Fraudulent Negligence/ Negligence Perform procedures/ Disclose confidential Improper

number of transgressions) conduct Incompetence in regarding patient interventions without information without professional

treating and caring for documents/records patient consent permission role conduct patients

Unlawful Criminal

Dental Therapy and Oral

31 (93.9\%)

(4)

Hygiene $(\mathrm{n}=33)$

Dietetics and Nutrition $(\mathrm{n}=7) \quad 1(14.3 \%)$

Emergency Care $(\mathrm{n}=49)$

$20(40.8 \%)$

$3(42.9 \%)$

$8(16.3 \%)$

Environmental Health $(\mathrm{n}=2)$

Medical and Dental $(\mathrm{n}=1121) \quad 558(49.8 \%)$

Medical Technology $(\mathrm{n}=1)$

Occupational Therapy, Medical

Orthotics, Prosthetics \& Arts

Therapy $(\mathrm{n}=6)$

Optometry and Dispensing

Opticians $(\mathrm{n}=84)$

Physiotherapy, Podiatry and

Biokinetics $(\mathrm{n}=39)$

Psychology $(\mathrm{n}=60)$

Radiography and Clinical

Technology $(\mathrm{n}=2)$

Speech, Language and Hearing

Professions $(\mathrm{n}=33)$

TOTAL $(\mathrm{n}=1437)$

$4(66.7 \%)$

$304(27.1 \%)$

$1(16.7 \%)$

72 (85.7\%)

$28(71.8 \%)$

$2(5.1 \%)$

$2(2.4 \%)$

$4(4.8 \%)$

$(7.1 \%)$

$14(23.3 \%)$

$14(23.3 \%)$

$2(5.1 \%)$

$4(10.3 \%)$

$3(7.7 \%)$

$2(100 \%)$

$1(1.7 \%)$

$2(3.3 \%)$

$7(11.7 \%)$

$22(36.7 \%)$

$15(45.5 \%)$

$13(39.4 \%)$

$743(51.7 \%)$

$347(24.1 \%)$

$53(3.7 \%)$

48 (3.3\%)

$15(1.0 \%)$

$5(15.2 \%)$

$198(13.8 \%)$

2 (6.1\%)

3 (42.9\%)

$7(34.7 \%)$

139 (12.4\%)

$1(100 \%)$

$28(2.5 \%) \quad 3(0.3 \%)$

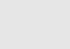

$3(0.2 \%)$


Table 5 - Actual transgression content descriptions per specific transgression category. The overall ten most frequent transgressions are indicated with superscript numbers $(1=$ most frequent transgression, $2=2$ nd most frequent transgression, and so forth).

Fraudulent conduct

Negligence/incompetence in treating/caring for patients

Improper professional role conduct

Negligence regarding patient documents/records

Perform procedures or interventions without patient consent

Unlawful conduct

Disclose confidential information without permission
- Charge for non-rendered services/procedures ${ }^{1}$

- Issuing misleading/inaccurate/false medical statement ${ }^{2}$

- Submit fraudulent medical aid claims ${ }^{3}$

- Charge for services rendered by an outsourced non-registered laboratory

- Issuing medical certificates/prescriptions without examining/seeing patient

- Misrepresentation of qualification/specialisation - Practice outside scope

- Failure to adequately and/or timeously assess/diagnose and manage/treat a patient's condition ${ }^{4}$

- Negligent/inappropriate administration/dosage/prescription/use of drugs ${ }^{6}$

- Failure to recognise/diagnose/manage post-operative/intervention complications $^{7}$

- Failure to refer patient to specialist when indicated (Medical and Dental) ${ }^{8}$

- Sub-standard/negligent surgical procedures ${ }^{10}$

- Perform unnecessary/inappropriate/obsolete surgery

- Perform surgical/interventions procedures while not qualified and/or sufficiently trained to do so ${ }^{9}$

- Verbal rude/derogatory/abusive behaviour towards patient that resulted in impaired patient dignity

- Failure to respond to HPCSA enquiry/investigation letter

- Negligent communication - Failure to communicate diagnosis and treatment with patient and/or family members

- Failure to keep/record proper records and clinical notes

- Issuing incomplete medical certificates/prescriptions not complying with HPCSA guidelines

- Failure to keep proper anaesthetic records of patient

- Failure to securely store/keep medical certificate/prescription book

- Failure to obtain patient consent for charging above-medical-aid fees

- Failure to obtain patient consent for intervention procedure (including pre-operative consent)

- Failure to inform patient of intervention risks

- Failure to adequately inform patient of alternative treatment options to surgery

- Treat a minor without parental consent

- Employ non-HPCSA-registered person as health professional ${ }^{5}$

- Practice as health professional when not registered with the HPCSA

- Allow an intern to practice as fully qualified health professional

- Unauthorised disclosure of patient information to 3rd party

- Discuss private medical matters in waiting room professionals towards critical ethical reflection, open debate and integrity.

- The HPCSA should reconsider the current trend of predominantly only imposing fines and suspended suspensions to healthcare professionals found guilty of ethics transgressions. Due to its inherent punitive nature such penalties cannot in themselves facilitate professional and ethical conduct (Godbold, 2008; Hoffmann \& Nortjé, 2015). Rather, the rehabilitation process for sanctioned healthcare professionals should include an ethics education component (e.g. attendance of an accredited healthcare ethics course or workshop).

\section{R E F E R E N C E S}

Brüggemann, J., Wijma, B., \& Swahnberg, K. (2012). Patients' silence following healthcare staff's ethical transgressions. Nursing Ethics, 19(6), 750-763.
Creswell, J. W. (2013). Steps in conducting a scholarly mixed methods study. In Discipline-based education research speaker series. Paper 48. Available at http://digitalcommons.unl.edu/ dberspeakers $/ 48$.

Department of Health. (2015). Ethics in health research: Principles, processes and structures (2nd ed., pp. 1-67). Pretoria: Department of Health.

Fischer, S. (2015). Patient choice and consumerism in healthcare: only a mirage of wishful thinking? In S. Gurtner, \& K. Soyez (Eds.), Challenges and opportunities in health care management. Geneve: Springer International Publishing.

Godbold, R. (2008). Physiotherapy and the new disciplinary process. New Zealand Journal of Physiotherapy, 36(2), 131-137.

Hoffmann, W. A., \& Nortjé, N. (2015). Ethical misconduct by registered physiotherapists in South Africa (2007-2013). South African Journal of Physiotherapy, 71(1). Art \#248, 7 pages. Available at http://www.sajp.co.za/index.php/sajp/article/ view/248.

HPCSA. n.d. How to lodge a complaint against a healthcare practitioner. Brochure, undated. Available at http://www.hpcsa.co.za.

Institute of Directors in Southern Africa. (2009). King report on Governance for South Africa. Institute of Directors in Southern Africa. 
Morse, J. M., \& Field, P. A. (1995). Qualitative research methods for health professionals (2nd ed.). Thousand Oaks: Sage.

Neuman, W. L. (1997). Social research methods: Qualitative and quantitative approaches (3rd ed.). Boston: Allyn and Bacon.

Nortjé, N., \& Hoffmann, W. A. (2014). Professional consequence for dentists involved in unethical decision-making in South Africa. Journal of Forensic Odonto-Stomatology, 32(Suppl.1), $22-29$.

Nortjé, N., \& Hoffmann, W. A. (2015a). Ethics misconduct among dietetic practitioners in South Africa (2007-2013). South African Journal of Clinical Nutrition, 28(2), 77-80.

Nortjé, N., \& Hoffmann, W. A. (2015b). Ethical misconduct by registered psychologists in South Africa during the period 2007-2013. South African Journal of Psychology, 45(2), $260-270$.
Ogubanjo, G. A., \& Knapp van Bogaert, D. (2014). Ethics in health care: healthcare fraud. South African Family Practice, 56(Suppl. 1), S10-S13.

Saunders, J. L., Barros-Bailey, M., Rudman, R., Dew, D. W., \& Garcia, J. (2007). Ethical complaints and violations in rehabilitation: an analysis of commission on rehabilitation counsellor certification data. Rehabilitation Counselling Bulletin, 51(1), 7-13.

Thomas, J. T. (2005). Licensing board complaints: minimizing the impact on the psychologist's defense and clinical practice. Professional Psychology Research and Practice, 36(4), 426-433.

Tritter, J. Q. (2009). Revolution or evolution: the challenges of conceptualizing patient and public involvement in a consumerist world. Health Expectations, 12(3), 275-287. 